\title{
Rare find in the intensive care unit: Human rhinomyiasis
}

\author{
J. Swol' ${ }^{1}$, S. Bockelmann ${ }^{1}$, A. Gurr ${ }^{2}$ and Th. A. Schildhauer ${ }^{1}$ \\ ${ }^{1}$ Department of Surgery, BG University Hospital Bergmannsheil, Bürkle-de-la-Camp Platz 1, 44789 Bochum, Germany \\ ${ }^{2}$ Otorhinolaryngology consultant, BG University Hospital Bergmannsheil, Bürkle-de-la-Camp Platz 1, 44789 Bochum, Germany
}

\begin{abstract}
The purpose is to report a case of human nasal myiasis found accidentally in a critically ill patient. This uncommon clinical condition is associated with poor hygiene, suppurative oral lesions, alcoholism and senility, and is quite rare in high income countries.

The patient was weaned and extubated after epifascial surgical abscess excision. Immediately after extubation the maggots appeared. The diagnosis was based on the visual observation of wriggling larvae about $1 \mathrm{~cm}$ in size. The larvae were identified as Calliphoridae. Treatment consisted of removal of the maggots. No further settlements have been found. The patient was without problems in the course and could be discharged home. On the origin of the maggots, we can find no plausible explanation.
\end{abstract}

\section{Report}

The purpose is to describe a case of human nasal myiasis found in a critically ill patient. Myiasis is derived from the Greek word, myia (fly), meaning invasion of vital tissue of humans or other mammals by fly larvae. Myiasis, first described by Hope in 1840, is characterized by larval infestation of body tissues or cavities of live individuals. Since then, many cases of myiasis affecting different human organs have been reported.

Cutaneous myiasis can be divided into three main clinical manifestations: furuncular, creeping (migratory), and wound (traumatic) myiasis. The flies that produce a furuncular myiasis include Dermatobia hominis, Cordylobia anthropophaga, Wohlfahrtia vigil, and the Cuterebra species. Gasterophilus and Hypoderma are two flies that produce a creeping myiasis. Flies that cause wound myiasis include screwworm flies such as Cochliomyia hominivorax and Chrysomya bezziana, and Wohlfahrtia magnifica [Robbins].

Male patient in his 70ties was referred to our hospital with previous history of sepsis with necrotizing fasciitis in his right thigh and multiorgan failure. As secondary findings acute renal failure, status after stroke, heart rhythm disorders and epilepsy were present. The fasciitis in his right thigh has been treated surgically with necrosectomy and fasciotomy in referral hospital. The patient suffered ventricular fibrillation and was resuscitated. The treatment included 24 hours post resuscitation hypothermia.

After admission to our hospital an abscess in his right thigh became apparent. The patient was promptly weaned and extubated after epifascial surgical abscess excision. Immediately after extubation the maggots appeared. The diagnosis was based on the visual observation of wriggling larvae about $1 \mathrm{~cm}$ in size. The larvae were identified as Calliphoridae. Treatment consisted of removal of the maggots. No further settlements have been found.

Copyright: $@ 2015$ Swol J. This is an open-access article distributed under the terms of the Creative Commons Attribution License, which permits unrestricted use, distribution, and reproduction in any medium, provided the original author and source are credited.
The patient was recovered in the course and discharged home. On the origin of the maggots, we can find no plausible explanation. Considering the rapid development of this species, the infection was likely acquired during the hospitalization.

\section{Discussion}

It refers to the infestation of live human and vertebrate animals with dipterous (two-winged) larvae (maggots) which, at least for a certain period, feed on the host's dead or living tissue, liquid bodysubstance, or ingested food [1].

This uncommon clinical condition is associated with poor hygiene, suppurative oral lesions, alcoholism and senility. Usually the condition affects individuals who are mentally challenged and physically not able to attend to their personal needs due to lack of psychomotor coordination. Occurrences of such cases are rare in developed countries and reflect the lack of special care for the vulnerable group of patients belonging to certain geographic areas [2].

Its diagnosis is made basically by the presence of larvae. Conventional treatment is the mechanical removal of the larvae, one by one, which is painful and embarrassing and repugnant to both health professional and patient.

\section{References}

1. Robbins K, Khachemoune A (2010) Cutaneousmyiasis: a review of the common types of myiasis. Int J Dermatol 49: 1092-1098. [Crossref]

2. Avula J, Avula H, Arora N, Manchukonda UK, Vivekavardhan Reddy N (2011) Orofacial Myiasis of the Gingiva and Nasal Cavity- A Report of Two Cases andGeneral Review. J Periodontol 82: 1383-1388. [Crossref]

Correspondence to: Justyna Swol, Department of Surgery, BG University Hospital Bergmannsheil, Bürkle-de-la-Camp Platz 1, 44789 Bochum, Germany; E-mail: jswol@icloud.com

Received: October 29, 2015; Accepted: November 19, 2015; Published: November 23, 2015 